\title{
Experimental Study on the Multistage Strength Degradation and the Associated Strain Energy Variation of S25C
}

\author{
Zihai Shi ${ }^{1, a^{*}}$, Masaaki Nakano, b, and Cuiping Liu ${ }^{1, \mathrm{c}}$ \\ ${ }^{1}$ Research and Development Centre, Nippon Koei Co., Ltd., 2304 Inarihara, Tsukuba, \\ Ibaraki 300-1259, Japan \\ aa4739@n-koei.co.jp, ba4753@n-koei.co.jp, a7614@n-koei.co.jp \\ * Corresponding author
}

\begin{abstract}
Keywords: Fatigue mechanism; Multistage strength degradation; Strain energy variation; Crack; Low carbon steel.
\end{abstract}

\begin{abstract}
The multistage strength degradation theory, which has recently emerged from studies on the material and structural behaviour of concrete, provides a clear description of the mechanism of fatigue. According to this theory, fatigue is caused by the sporadic sudden change of cracking behaviour in a system under cyclic loading, leading to intermittent strength reduction of the system and its eventual failure. As metal is the main engineering material plagued most by fatigue failure, this newly-established theory needs to be experimentally verified on metal, which is the aim of this study. The obtained test results present strong experimental evidence for the existence of multistage strength degradation processes in metals under cyclic loading, and the strength degradation is clearly triggered by the abrupt change of cracking behaviour. These tests confirm the relevance of the multistage strength degradation theory on metal fatigue, and the engineering implications of the study are discussed.
\end{abstract}

\section{Introduction}

The multistage strength degradation theory, which has recently emerged from studies on the material and structural behaviour of concrete [1,2], provides a clear description of the fatigue mechanism that has been the focus of extensive research since the early nineteenth century [3-5]. According to this theory, fatigue is caused by the sporadic sudden change of cracking behaviour in a system under cyclic loading, leading to intermittent strength reduction of the system and its eventual failure. Following clarification of the fatigue mechanism, further studies on the strain energy variation of a concrete beam that had experienced periodic strength degradation due to repeated loading revealed a waveform variation in the total strain energy of the beam [6]. Fig. 1 shows schematic illustrations of multistage strength degradation of a system under fatigue and the corresponding strain energy diagram. As seen from Fig. 1(b), a strain energy diagram shows the accumulation and release of the total strain energy of the system at its ultimate strength, synchronising with the cycle of strength degradation.
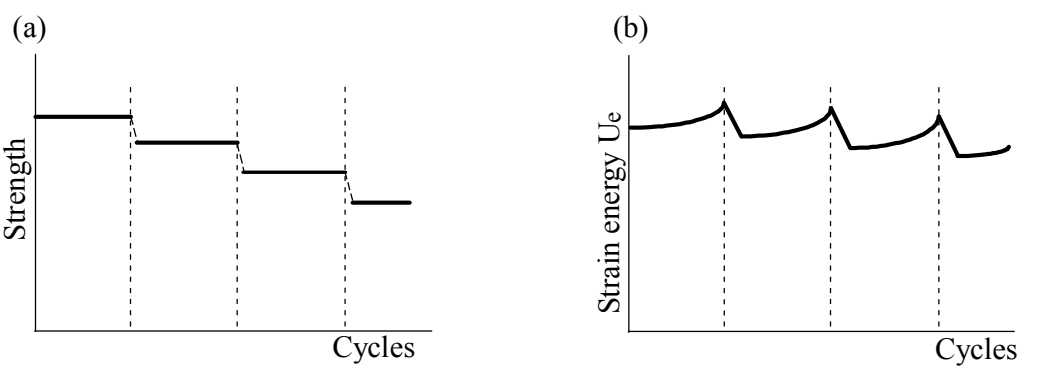

Fig. 1 Conceptual illustrations of multistage strength degradation and strain energy diagram: (a) A multistage strength degradation process under cyclic loading; (b) A strain energy diagram in association with the process of multistage strength degradation [6]. 
As metal is the main engineering material suffering most from fatigue failure, these newly-established theories need to be experimentally verified on metal, which is the purpose of this study. In the following, the scheme of the experimental study is explained first. Then, test results on multistage strength degradation and strain energy variation are presented and discussed, using the severity of cracking of test specimens as a main index for damage classification. Finally, possible applications of the new theory on metal fatigue are discussed and conclusions are drawn.

\section{Scheme of Experimental Study}

The material tested was $\mathrm{S} 25 \mathrm{C}$, which was annealed at $850^{\circ} \mathrm{C}$ for $1 \mathrm{~h}$ followed by furnace cooling. The chemical composition of the material is shown in Table 1. Fig. 2 shows the specimen geometry and the two-step test procedures. As illustrated, a test specimen underwent a number of torsional cyclic loadings first, and then a tension test was carried out to obtain the ultimate tensile strength of the preloaded specimen. The cyclic loads were applied to propagate cracks in the specimen to investigate how the propagation of cracks affects the material strength, and how strength degradation takes place in metal under fatigue.

The reason for using torsional loads was to ensure stable crack growth in a test specimen for a designated number of cyclic loadings. In order to choose a suitable stress amplitude at which to apply the cyclic loads and to determine the other testing conditions for the experiment, a torsional fatigue test was performed first to obtain the S-N curve, which is shown in Fig. 3. The stress ratio of the test was -1 , and the S-N data were obtained by employing two torsional fatigue testing machines for crosschecking. The test was carried out in open air at a rotational speed of $2000 \mathrm{cpm}$ (Photo 1). Note that a fatigue failure $\left(N_{f}\right)$ was defined as the number of cycles when the increment in the rotational

Table 1 Chemical composition [wt \%]

\begin{tabular}{ccccccccc}
\hline $\mathrm{C}$ & $\mathrm{Si}$ & $\mathrm{Mn}$ & $\mathrm{P}$ & $\mathrm{S}$ & $\mathrm{Cu}$ & $\mathrm{Ni}$ & $\mathrm{Cr}$ & $\mathrm{CC} 9$ \\
\hline 0.24 & 0.26 & 0.46 & 0.019 & 0.005 & 0.02 & 0.01 & 0.03 & 0.04 \\
\hline
\end{tabular}

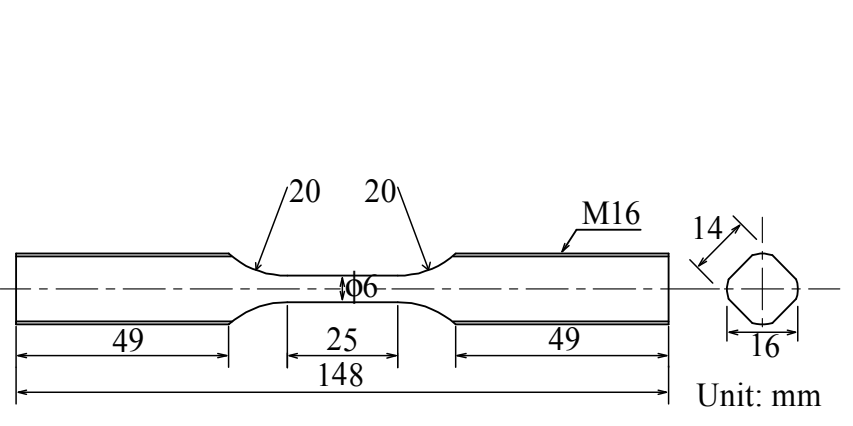

(a)

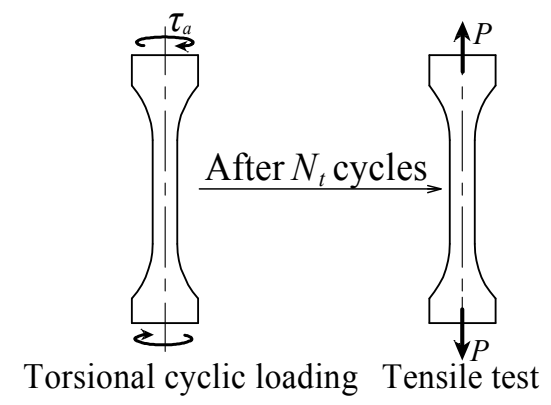

(b)

Fig. 2 Specimen geometry and test procedures

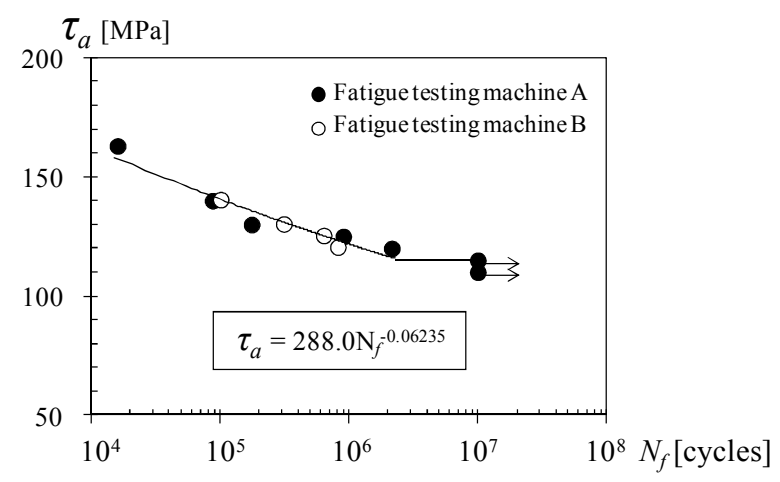

Fig. 3 S-N curve

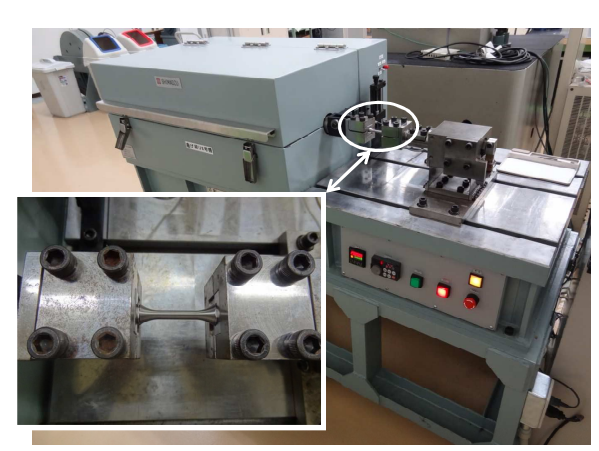

Photo 1 Torsional fatigue test 
amplitude reached $3.375 \mathrm{~mm}$ during the test, which was approximately equivalent to an increment of $1 \mathrm{deg}$. The shear stress amplitude, $\tau_{a}$, is obtained as

$$
\tau_{a}=M_{a} \cdot d /\left(2 I_{p}\right)
$$

where $M_{a}=$ rotational moment amplitude; $I_{p}=\pi d^{4} / 32$, polar moment of inertia; and $d=$ diameter.

As shown in Fig. 3, the maximum amplitude of shear stress tested was $163 \mathrm{MPa}$ and fatigue failure occurred at $1.6 \times 10^{4}$. The fatigue limit was reached at the stress amplitude of $115 \mathrm{MPa}$, i.e., no failure at $1.0 \times 10^{7}$. In order to facilitate quick crack propagation in a test specimen to reduce the total testing time of the experiment, the stress amplitude for the detailed incremental load-cycle tests was chosen as $140 \mathrm{MPa}$ ( $\tau_{y}=143 \mathrm{MPa}$ based on the von Mises yield criterion), and the $N_{f}$ of the two S-N data at this stress amplitude were $8.8 \times 10^{4}$ and $1.0 \times 10^{5}$, respectively. Therefore, a series of cyclic loading tests under the condition of $\tau_{a}=140 \mathrm{MPa}$ was carried out from $N_{t}$ of $5.0 \times 10^{4}$ (no cracks were observed up to this point) to $N_{t}$ of $1.0 \times 10^{5}$ (with one exception), with a load-cycle increment of $5.0 \times 10^{3}$. After imposing various loading histories on the test specimens, all the specimens including those of the S-N tests underwent tension tests to obtain the ultimate tensile strength for each test specimen.

Table 2 Test conditions and experimental results of ultimate tensile strength

\begin{tabular}{|c|c|c|c|c|c|c|c|c|c|c|c|c|c|}
\hline TPNo & $\begin{array}{c}\tau_{a} \\
{[\mathrm{MPa}]}\end{array}$ & $\begin{array}{c}N_{f}(*), N_{t} \\
{[\text { cycle] }}\end{array}$ & $\begin{array}{l}\text { Crack } \\
\text { grade }\end{array}$ & $\begin{array}{c}\sigma_{u} \\
{[\mathrm{MPa}]}\end{array}$ & $\begin{array}{c}\text { Elng } \\
{[\%]}\end{array}$ & $\begin{array}{l}d / D \\
{[\%]}\end{array}$ & TPNo & $\begin{array}{c}\tau_{a} \\
{[\mathrm{MPa}]}\end{array}$ & $\begin{array}{c}N_{f}\left({ }^{*}\right), N_{t} \\
{[\text { cycle] }}\end{array}$ & $\begin{array}{l}\text { Crack } \\
\text { grade }\end{array}$ & $\begin{array}{c}\sigma_{u} \\
{[\mathrm{MPa}]}\end{array}$ & $\begin{array}{c}\text { Elng } \\
{[\%]}\end{array}$ & $\begin{array}{l}d / D \\
{[\%]}\end{array}$ \\
\hline 1 & - & - & - & 446 & 31.5 & 55.3 & 29 & 140 & $8.0 \mathrm{E}+04$ & A & 458 & 34.5 & 52.9 \\
\hline 2 & - & - & - & 444 & 33.5 & 54.8 & 30 & 140 & $6.5 \mathrm{E}+04$ & B & 394 & 12.0 & 17.4 \\
\hline 3 & - & - & $\therefore$ & 440 & 36.0 & 55.9 & 31 & 140 & $8.0 \mathrm{E}+04$ & A & 458 & 34.0 & 52.4 \\
\hline 4 & 163 & $1.6 \mathrm{E}+04 *$ & $\mathrm{E}$ & 151 & 5.5 & - & 32 & 140 & $8.0 \mathrm{E}+04$ & A & 458 & 21.0 & 34.1 \\
\hline 5 & 120 & $2.1 \mathrm{E}+06^{*}$ & D & 313 & 12.5 & 5.4 & 33 & 140 & $8.0 \mathrm{E}+04$ & A & 464 & 30.0 & 52.4 \\
\hline 6 & 140 & $8.8 \mathrm{E}+04 *$ & D & 271 & 8.5 & 11.8 & 34 & 140 & $6.2 \mathrm{E}+04$ & $\mathrm{C}$ & 369 & 8.0 & 11.6 \\
\hline 7 & 110 & $1.0 \mathrm{E}+07$ & A & 441 & 35.5 & 52.8 & 35 & 140 & $7.8 \mathrm{E}+04$ & $\mathrm{C}$ & 373 & 12.0 & 13.7 \\
\hline 8 & 130 & $1.8 \mathrm{E}+05^{*}$ & B & 388 & 14.5 & 17.6 & 36 & 140 & $7.5 \mathrm{E}+04$ & A & 455 & 27.5 & 37.5 \\
\hline 9 & 125 & $9.0 \mathrm{E}+05^{*}$ & E & 171 & 3.5 & - & 37 & 140 & $7.5 \mathrm{E}+04$ & A & 461 & 31.0 & 52.3 \\
\hline 10 & 115 & $1.0 \mathrm{E}+07$ & A & 447 & 32.0 & 52.6 & 38 & 140 & $7.5 \mathrm{E}+04$ & A & 459 & 28.5 & 54.5 \\
\hline 11 & 130 & $3.2 \mathrm{E}+05^{*}$ & $\mathrm{E}$ & 178 & 6.0 & - & 39 & 140 & $7.5 \mathrm{E}+04$ & A & 456 & 33.5 & 54.3 \\
\hline 12 & 125 & $6.4 \mathrm{E}+05^{*}$ & $\mathrm{E}$ & 210 & 8.0 & 1.6 & 40 & 140 & $6.5 \mathrm{E}+04$ & A & 458 & 33.0 & 52.1 \\
\hline 13 & 140 & $1.0 \mathrm{E}+05^{*}$ & B & 407 & 13 & 14.29 & 41 & 140 & $6.5 \mathrm{E}+04$ & A & 458 & 27.0 & 52.4 \\
\hline 14 & 120 & $8.3 \mathrm{E}+05^{*}$ & $\mathrm{E}$ & 192 & 3.5 & 2.4 & 42 & 140 & $6.5 \mathrm{E}+04$ & A & 456 & 34.5 & 52.3 \\
\hline 15 & 140 & $6.1 \mathrm{E}+04$ & $\mathrm{~B}$ & 407 & 16.0 & 20.8 & 43 & 140 & $6.5 \mathrm{E}+04$ & A & 457 & 32.0 & 51.7 \\
\hline 16 & 140 & $6.5 \mathrm{E}+04$ & B & 434 & 18.0 & 20.6 & 44 & 140 & $6.0 \mathrm{E}+04$ & A & 452 & 19.5 & 29.0 \\
\hline 17 & 140 & $5.0 \mathrm{E}+04$ & A & 463 & 32.0 & 47.6 & 45 & 140 & $6.0 \mathrm{E}+04$ & A & 462 & 30.0 & 52.4 \\
\hline 18 & 140 & $5.0 \mathrm{E}+04$ & A & 459 & 30.0 & 47.8 & 46 & 140 & $8.5 \mathrm{E}+04$ & B & 411 & 15.5 & 14.6 \\
\hline 19 & 140 & $5.0 \mathrm{E}+04$ & A & 458 & 38.0 & 52.7 & 47 & 140 & $8.5 \mathrm{E}+04$ & E & 166 & 4.5 & 1.4 \\
\hline 20 & 140 & $7.3 \mathrm{E}+04$ & B & 419 & 19.0 & 29.6 & 48 & 140 & $8.5 \mathrm{E}+04$ & $\mathrm{C}$ & 373 & 12.0 & 14.1 \\
\hline 21 & 140 & $6.0 \mathrm{E}+04$ & A & 462 & 32.0 & 54.3 & 49 & 140 & $8.5 \mathrm{E}+04$ & $\mathrm{C}$ & 366 & 12.5 & 11.7 \\
\hline 22 & 140 & $6.0 \mathrm{E}+04$ & A & 454 & 33.0 & 54.6 & 50 & 140 & $9.0 \mathrm{E}+04$ & $\mathrm{C}$ & 363 & 10.0 & 8.4 \\
\hline 23 & 140 & $1.3 \mathrm{E}+05$ & $\mathrm{D}$ & 287 & 15.0 & 7.3 & 51 & 140 & $9.0 \mathrm{E}+04$ & B & 436 & 19.5 & 25.7 \\
\hline 24 & 140 & $7.6 \mathrm{E}+04$ & A & 444 & 17.0 & 26.3 & 52 & 140 & $8.0 \mathrm{E}+04$ & B & 425 & 15.0 & 17.7 \\
\hline 25 & 140 & $7.0 \mathrm{E}+04$ & A & 456 & 32.5 & 50.5 & 53 & 140 & $9.0 \mathrm{E}+04$ & C & 362 & 4.0 & 4.1 \\
\hline 26 & 140 & $7.0 \mathrm{E}+04$ & A & 458 & 32.5 & 49.8 & 59 & - & 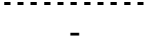 & - & 439 & 36.5 & 55.9 \\
\hline 27 & 140 & $7.0 \mathrm{E}+04$ & A & 457 & 29.0 & 48.0 & 60 & - & - & - & 434 & 37.5 & 55.9 \\
\hline 28 & 140 & $8.2 \mathrm{E}+04$ & B & 394 & 11.5 & 13.3 & 61 & - & - & - & 447 & 33.0 & 53.5 \\
\hline
\end{tabular}

Note: Elng = percent elongation; $d / D=$ contraction percentage. 


\section{Experimental Results}

Multistage Strength Degradation. Table 2 shows the test piece number, test conditions and experimental results. The average ultimate tensile strength of the six virgin specimens was $442 \mathrm{MPa}$. As seen, the severity of cracking of a test specimen after experiencing the designated number of cyclic loadings was divided into five grades: A, B, C, D and E. A typical sample crack for each grade is shown in Photo 2, where Grade $\mathrm{A}=$ almost invisible crack; Grade $\mathrm{B}=$ visible hair-like crack; Grade $\mathrm{C}$ = clearly visible crack; Grade $\mathrm{D}=$ severe crack; and Grade $\mathrm{E}=$ penetrating crack. Though in principle three tests were performed under each test condition, in some cases one or two extra tests were also carried out for verification. Fig. 4(a) shows the relationships of the ultimate tensile strengths of all the test specimens (including those of the $\mathrm{S}-\mathrm{N}$ tests) versus the load cycles imposed, using the crack grading as a principal index of the multistage strength degradation of the test specimens with various crack-related damages. The average strength of each grade is represented by a solid line, and for comparison the average strength of the virgin specimens is shown by a dotted line.

As seen from Fig. 4(a), while the average strength of grade A specimens slightly increased from that of the virgin specimens by $3 \%$, apparently due to work hardening, the average strengths of the other groups in the order of grade B to grade E decreased by $7 \%, 17 \%, 34 \%$ and $60 \%$, respectively.

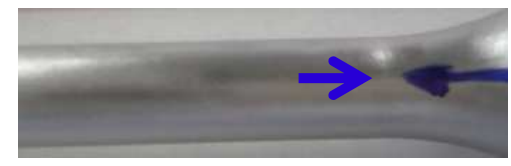

Grade A

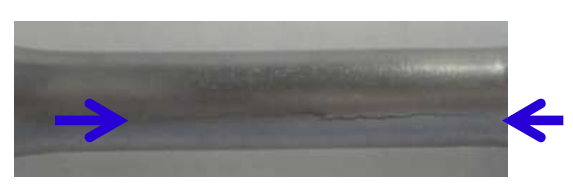

Grade D

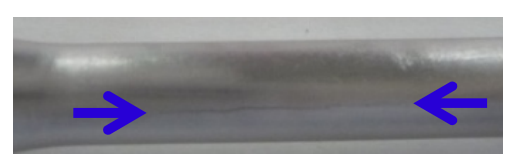

Grade B

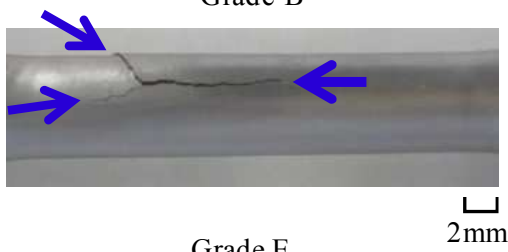

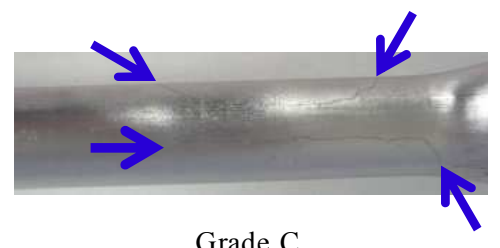

Grade A: Almost invisible crack Grade B: Visible hair-like crack Grade C: Clearly visible crack Grade D: Severe crack Grade E: Penetrating crack

Photo 2 Five grades for classifying the degree of severity of crack damage and propagation in test specimens with cyclic loading history

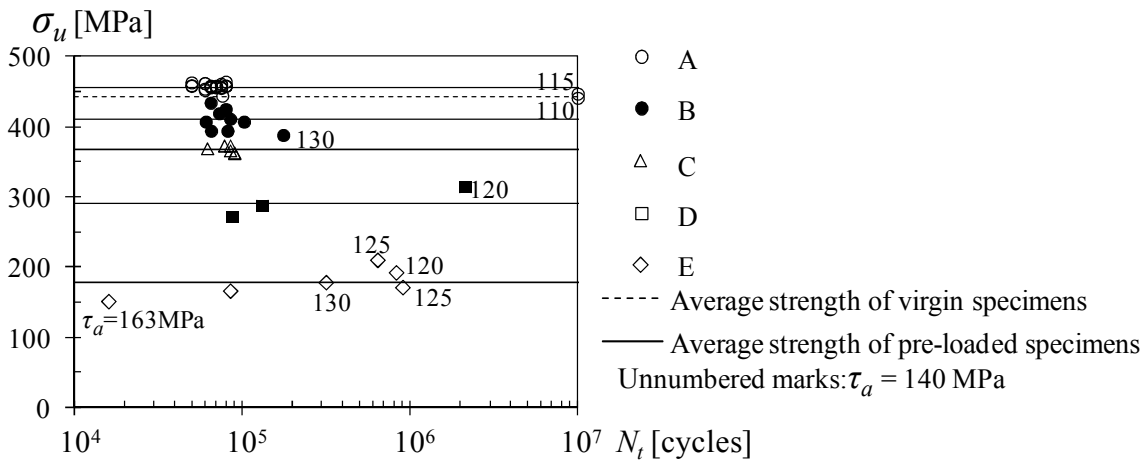

Fig. 4(a) Multistage strength degradations based on the advance of crack grades

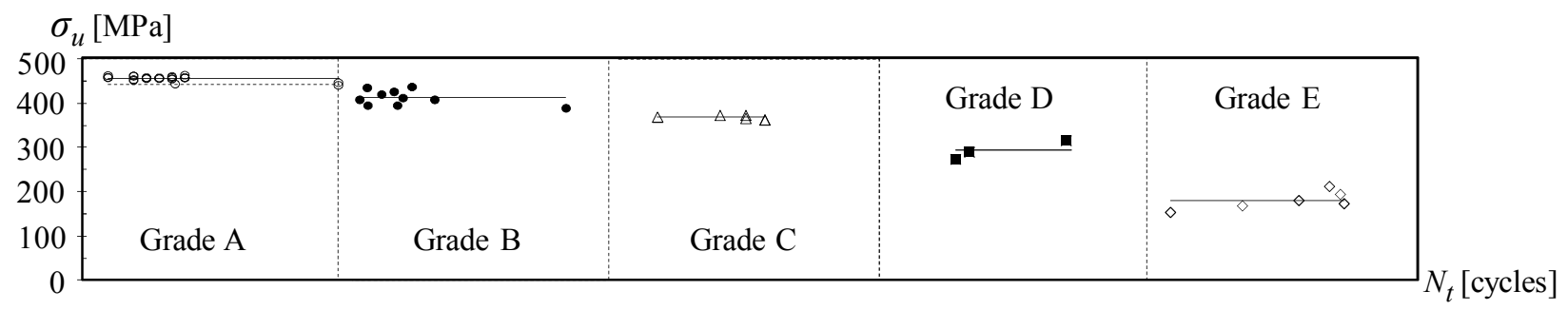

Fig. 4(b) Multistage strength degradations based on the order of crack grades 
The appropriateness of using the present crack grading method for classification of multistage strength degradation was shown by the limited scatter of the individual data from the strength average in each group. Fig. 4(b) shows the multistage strength degradations in the order of crack grades, which is the natural order of crack initiation and growth in a structural member or a machine part under fatigue. With the constant stress amplitude of $\tau_{a}=140 \mathrm{MPa}$, the strength of the specimens experienced a complete variation of grades, i.e., from A to E, even though the grade E test data were mainly composed of test specimens with smaller stress amplitudes of 120 to $130 \mathrm{MPa}$ and in a much higher cyclic loading range. As expected, the test specimen with the highest stress amplitude of 163 $\mathrm{MPa}$ and the lowest loading cycles of $1.6 \times 10^{4}$ also fell into grade E. It is worth noting that among the grade A specimens, the ultimate tensile strengths of the two S-N test specimens at the fatigue limit remained virtually as strong as the virgin specimens, and they showed no evidence of work hardening due to the much smaller stress amplitudes endured during cyclic loading.

Strain Energy Variation. Fig. 5 shows the load-displacement relations of all the test specimens obtained by tensile tests. Based on these relations, the total strain energy at the maximum load and at the failure load were calculated separately for each preloaded specimen and the results are shown in Fig. 6(a) and 6(b), respectively. Following the example of Fig. 4(b), the same results are also shown in the order of crack grading in Fig. 7(a) and 7(b), which clearly show the variation of total strain energy with the increase of load cycles in each crack grade. As the severity of cracking progresses and the

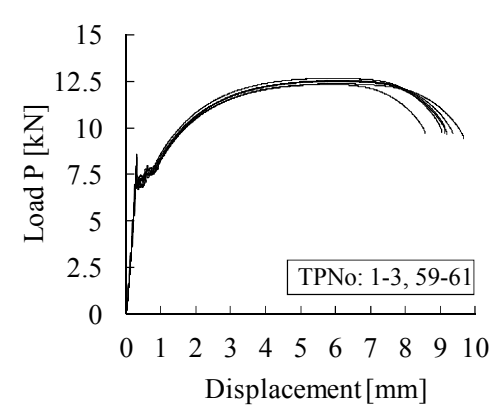

(a) Virgin specimens

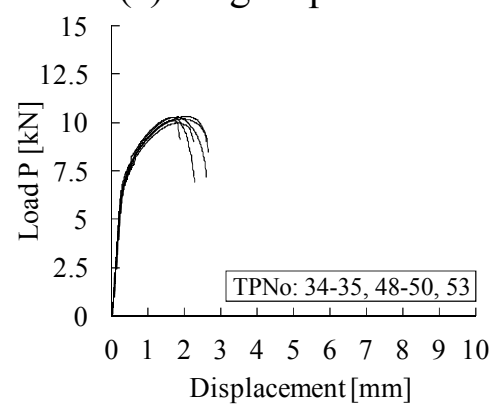

(d) Grade C

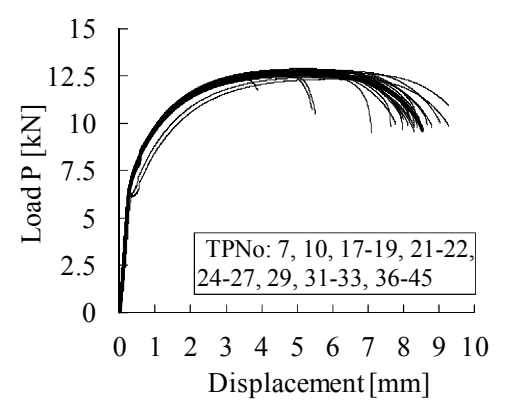

(b) Grade A

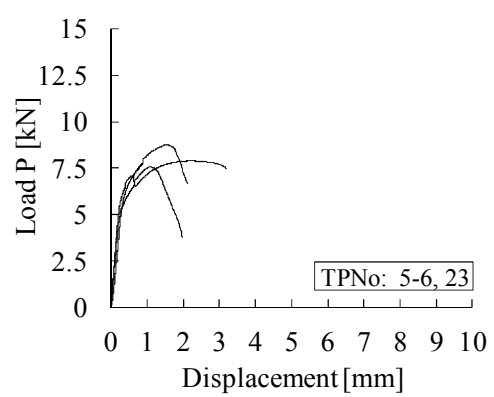

(e) Grade D

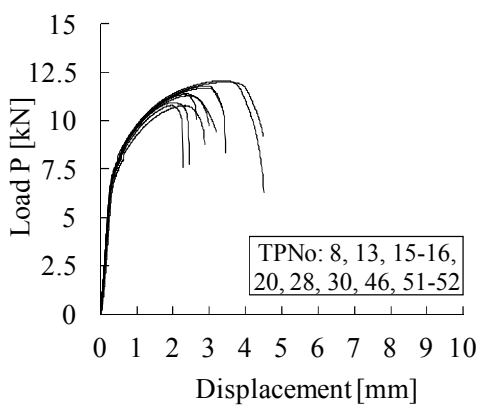

(c) Grade B

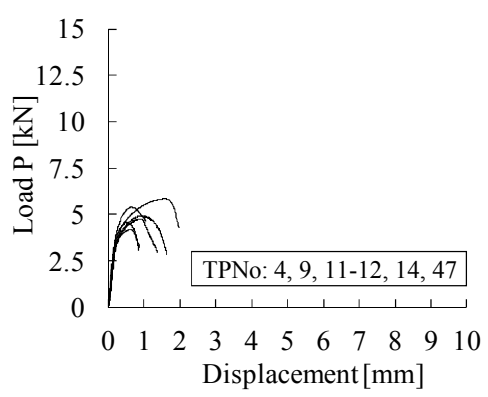

(f) Grade E

Fig. 5 Load-displacement relations of test specimens

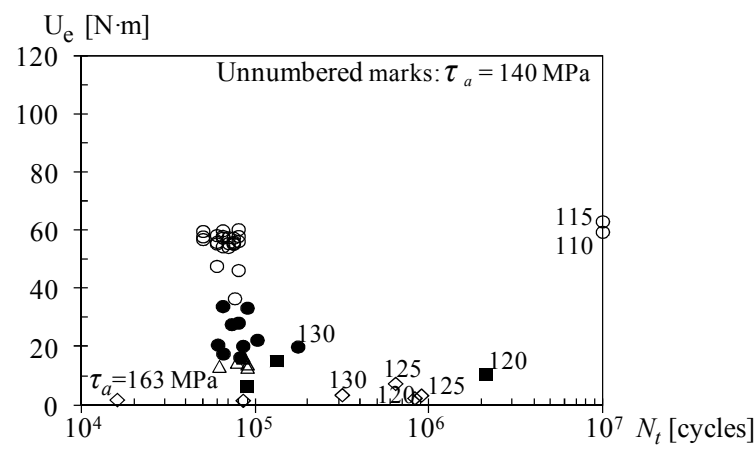

(a) At the maximum load

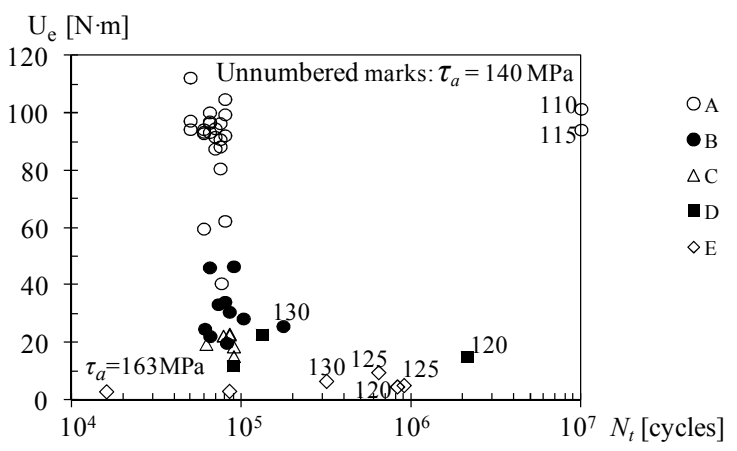

(b) At the failure load

Fig. 6 Total strain energies of test specimens 


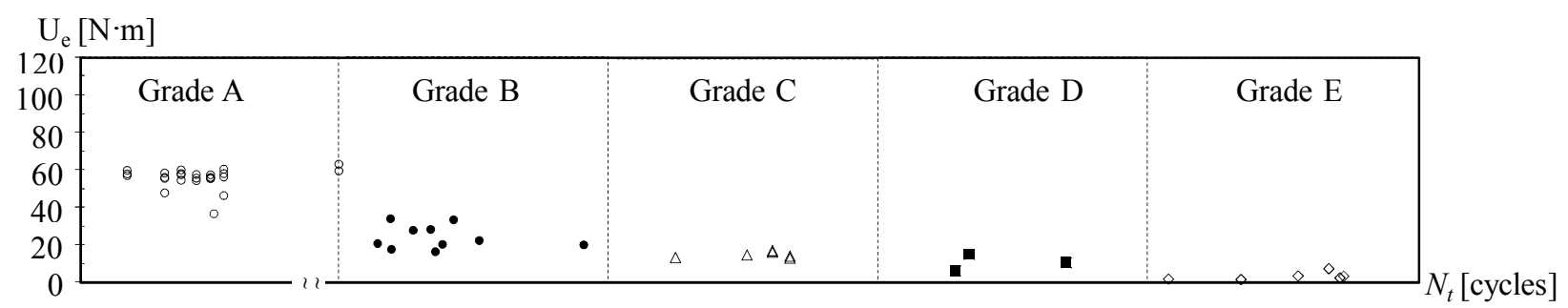

(a) At the maximum load

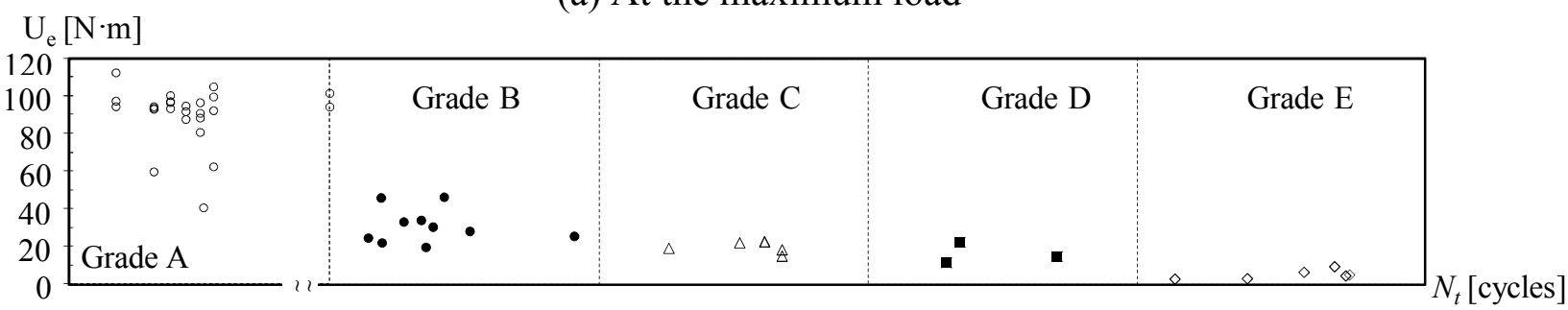

(b) At the failure load

Fig. 7 Strain energy variations based on the order of crack grades

material becomes fragile, the total strain energy decreases rapidly and the two energy states become similar. Due to the lack of sufficient test data, especially regarding the advanced crack grades of C, D and $\mathrm{E}$, further discussion on strain energy variation is not realistic at this stage of study.

\section{Conclusions}

The obtained test results in Figs. 4 and 5 present strong experimental evidence for the existence of the multistage strength degradation processes in metals under cyclic loading, and the strength degradation is clearly triggered by the abrupt change of cracking behaviour, or the crack grade. These tests confirm the relevance of the multistage strength degradation theory on metal fatigue, which in principle cannot be verified directly on the same test specimen by experiments (obviously, because the ultimate material strength can only be obtained by actually fracturing the test specimen itself). By testing multiple identical specimens under varying cyclic loading conditions, however, the general trend and relation for strength degradation can be established, as presented and discussed above.

As for its application, the multistage strength degradation theory may offer an alternative design theory to the S-N curve in fatigue design, which in essence is a strength-based design theory with the degraded material strength being derived from an experimentally-established multistage strength degradation relation with a well-defined stress range, based on the design life. Compared with the S-N curve, the scatter in such a relation is predictably much smaller because it is obtained under stable test conditions, and hence its application may fundamentally improve the safety and economy of fatigue design.

\section{References}

[1] Z. Shi, Crack Analysis in Structural Concrete: Theory and Applications, Elsevier, Burlington, 2009.

[2] Z. Shi, Y. Nakamura, M. Nakano, Numerical studies on multistage strength degradation of notched concrete beams under sequential loading, I. J. Fatigue 33 (2011) 1140-1150.

[3] A. Wöhler, Versuche über die Festigkeit der Eisenbahnwagenachsen, Zeitschrift für Bauwesen 10; English summary (1867), Engineering 4 (1860), 160-161.

[4] W. Fairbairn, Experiments to determine the effect of impact, vibratory action, and long continued changes of load on wrought iron girders, Philosophical Transactions of the Royal Society, London 154 (1864) 311.

[5] J. A. Ewing, J. C. Humfrey, The fracture of metals under rapid alterations of stress, Philosophical Transactions of the Royal Society, London A200 (1903) 241-250.

[6] Z. Shi, Y. Nakamura, M. Nakano, Strain energy diagram for characterizing fatigue behaviour, in:

T. E. Simos (Ed.), ICNAAM 2012, AIP Conference Proceedings 1479 (2012) 2162-2165. 